\title{
Reconfigurable Manufacturing: How Shop Floor Digitalisation Supports Operators in Enhancing Diagnosability
}

\author{
Alessia NAPOLEONE ${ }^{\mathrm{a}, 1}$ and Ann-Louise ANDERSEN ${ }^{\mathrm{b}}$ \\ ${ }^{a}$ Department of Management, Economics and Industrial Engineering, Politecnico di \\ Milano, Milano, Italy \\ ${ }^{\mathrm{b}}$ Department of Materials and Production, Aalborg University, Aalborg, Denmark
}

\begin{abstract}
Manufacturing companies are currently struggling with the need to deal with ever changing marker requirements and technological advances. They can develop the reconfigurability capability in their factories in order to deal with such context. Moreover, companies can implement shop floor digitalisation to enhance their reconfigurability. This paper sustains two arguments: (i) the possibility to enhance diagnosability as a critical reconfigurability characteristic through shop floor digitalisation; and (ii) the relevance of the human role in reaching diagnosability in a digitalised shop floor. The paper first presents a literature review and based on this, aspects of shop floor digitalisation supporting operators in enhancing the diagnosability are identified and synthesized in a 3-e model (error reduction, ergonomics, and easiness). Secondly, insights from a case study are interpreted through the literature-based model in order to both consolidate the theoretical results and emphasize the implications for practitioners. The findings of this paper indicate that the proposed model can support practitioners in taking specific actions in regard to shop floor digitalisation in order to improve operatordependent diagnosability and, in turn, the reconfigurability capability.
\end{abstract}

Keywords. Reconfigurability, diagnosability, shop floor digitalisation, operator 4.0

\section{Introduction}

Nowadays manufacturing companies need to develop the reconfigurability capability in order to deal with ever changing market requirements and technological advances [1], [2],[3]. Reconfigurability is the capability of a manufacturing system to repeatedly change and/or rearrange its components in a cost-effective way in order to quickly adjust production capacity and functionality to accommodate evolving market requirements [4],[5]. An important characteristic of reconfigurability is diagnosability, i.e. the capability to (i) quickly identify sources of quality and reliability problems [2] and (ii) quickly correct operational problems [1]. In other words, diagnosability, which main effect is the reduction of the ramp-up time after reconfigurations [6], allows fast solution of any quality or reliability problem incurring during the reconfiguration of modular and integrable production resources. Thus, diagnosability is an important reconfigurability characteristic as it allows faster reconfiguration and ramp-up of production systems.

\footnotetext{
${ }^{1}$ Corresponding Author. Alessia.napoleone@polimi.it
} 
A recent trend in manufacturing is factory digitalisation, which means achieving a connected manufacturing system that uses a continuous stream of data from connected operations and production systems to learn and adapt to new requirements [7], [8]. Thus, digitalisation is indeed an enabler of reconfigurable manufacturing [9],[10],[11].

Digitalisation makes a broad spectrum and large amount of data of various types available. Some of this relevant data comes from and/or is directed to the shop floor and its proper exploitation provides many benefits to the factory (see for example [12]). When focusing on the shop floor, diagnosability is one of the reconfigurability characteristics most impacted by digitalisation, however, limited previous research has focused either on how to increase reconfigurability through digitalisation or explicitly on the impacts of digitalisation on diagnosability (this is evident in the scarce literature reached by combining such keywords on Scopus and Web of Science (WoS), as pointed out in Section 1). Furthermore, many authors have remarked the important role of operators in a digitalised shop floor (see for example [13]). This is another relevant argument taken into consideration in this paper, due to its implications on diagnosability and reconfigurability of manufacturing systems. Indeed, the role of humans, seen as marginal compared to machines in the infancy of theory on reconfigurable manufacturing [2], has increased in relevance in reconfigurability-related literature, due to the inner adaptability and context-awareness of human resources [14], [15]. Moreover, the ability to change the level of automation in a manufacturing system i.e. automatibility is today considered an additional characteristic of reconfigurability [16], meaning that operators and manual work is considered an important enabler of reconfigurability.

Therefore, this paper sustains two arguments: (i) the possibility to enhance diagnosability as a critical reconfigurability characteristic through shop floor digitalisation; and (ii) the relevance of the human role in terms of enhancing diagnosability in a digitalised shop floor. Specifically, the research question addressed in this paper is: "How can shop floor digitalisation support operators in enhancing the diagnosability and thus the reconfigurability capability of the manufacturing system?"

Thus, in the remainder of this paper, section 1 describes the adopted research methodology and approach: a structured literature review followed by a case study. Section 2 reports the theoretical results by describing a model that summarises the aspects of shop floor digitalisation supporting operators in enhancing the diagnosability. Section 3 interprets insights on a case study through the literature-based model to both consolidate the theoretical results and show the implications of this study for practitioners. Finally, section 4 concludes and provides directions for future research.

\section{Methodology}

In order to address the research question, a literature review was initially carried out including both analysis and synthesis of previous research. Hereafter, a literature-based model was used to create and summarise insights from a case study on how practitioners can enhance shop floor digitalisation supporting operators in order to eventually enhance diagnosability and reconfigurability.

The analysis of literature aimed at identifying the aspects of shop floor digitalisation supporting operators in enhancing the diagnosability. To this end, a structured literature review was performed. Specifically, the review took into account the peculiarities of the operations management field compared to other fields and used the guidelines provided by Durach, Kembro and Wieland [17]. The search databases used for the investigation 
were Scopus and WoS. To ensure the coverage of the purpose of this research, firstly the keywords "digitalisation" (or "cyber-physical system") and "diagnosability" were combined through an "AND" Boolean operator and 11 papers in total were reached and analysed. Secondly, "digitalisation" and "operator" (or "worker") and "factory" (or "shop floor") were combined through an "AND" Boolean operator and a total of 25 articles were identified and analysed. The analysis of the articles aimed at identifying any possible statement referred to any achievement in terms of diagnosability (e.g. reduction of errors, improvement of production quality) through digitalisation. To do so, abstracts were initially read; moreover, specific diagnosability-related keywords were searched within the full text of articles (such as diagnostics, quality, reliability, error/mistake, unexpected event, ramp-up time and so on); finally, any possible observation on operators/workers was also searched within the full text of articles and analysed. Identified observations were coded in a database, also reporting all citation information. As a result, based on 12 contributions, the proposed 3-e model (error reduction, ergonomics, and easiness) was built, as synthesized in section 2 . The model exploits observations from literature to synthesize the three aspects of shop floor digitalisation supporting operators in enhancing the diagnosability.

To consolidate the theoretical results and show the implications of this study for practitioners, a descriptive case study was conducted [18], [19]. The purpose of the case study was to create insights on how the model can be applied to analyse opportunities for enhancing shop floor digitalisation supporting operators in practise. A large and mature manufacturing company, operating in an international and increasingly uncertain market, was selected as it is currently implementing an experimental project aimed at the digitalisation of the entire factory. To gather information in the case, multiple sources of evidence in the company were assessed [20], such as company documents on the project, participation in critical meetings related to the project, open-ended interviews, as well as direct observations. Information was collected over a time horizon of a year. The main stakeholders involved in the project, thus providing valuable information for the analysis, were members of the IT department, production managers, members of the process engineering department, key users and operators within the factory, and IT solution providers. To properly analyse the data of the case study, acquired information was transcribed and coded [20]: fragmented or taken apart information was grouped and then summarised into the three literature-based classes of the aforementioned 3-e model (error reduction, ergonomics, and easiness). To ensure the validity of the analysis, the results of the analysis (synthesized in section 3, specifically in Table 2) were sent to the informants for review purposes [20].

\section{Results from literature review}

The results of the structured literature review are twofold; firstly, literature suggests that, as foreseeable, shop floor digitalisation enhances diagnosability; secondly, some relevant aspects supporting operators in enhancing the diagnosability of a shop floor are identified.

The following literature-based statements support that shop floor digitalisation enhances diagnosability. 
- Richter et al. [21] included "reduced down time, increased quality and less waste, as well as greater visibility of the manufacturing floor" among the benefits of shop floor digitalisation. For example, they remarked that paperbased information exchange between operators often leads to delays or redundant work.

- Belli et al. [22] presented the digitalisation process implemented in a company in order to improve performances of production departments. They witnessed some interesting results of the company, such as the reduction of errors and nonconformity, appropriately quantified in a saving range and improvements of the know-how of the company.

- Umer et al. [12] remarked the relevance of event-driven architectures deployed at shop floor level to collect data from various types of equipment and conversion of these in real time into more meaningful data. The data collected from such equipment can be used for optimizing the production or for pinpointing the source of quality defects.

- Some authors specifically referred to the positive impacts of Augmented Reality (AR) supported tasks in terms of task completion time and error rates [23], [24].

Above all, the analysis of literature led to the identification of aspects that support operators in enhancing the diagnosability of a shop floor and influence the quality of the solution for operators. Indeed, some authors manifested sensitivity to the need to prepare operators and to increase their acceptance of digitalisation [25]. According to Richter et al. [21] people who were not born into the digital era are likely to experience some difficulties in accepting technology related changes at work. Moreover, Wurhorfer et al. [26] addressed the need to appropriately design digital solutions to effectively support operators, thus avoiding ineffective solutions.

Overall, by reviewing literature, the authors derived three classes of aspects of shop floor digitalisation supporting operators in enhancing the diagnosability; these are:

- $\quad$ error reduction through either error-proof mechanism or the enhancement of their knowledge (error avoidance by providing knowledge to workers);

- $\quad$ ergonomics of the solution;

- easiness of consultation/ declarations.

While the impact of the first aspect on diagnosability is immediate (avoiding errors would improve the quality and reliability of production), the other two aspects influence the quality of the solution to operators and, in turn, affect the diagnosability (e.g. an easier consultation of the solution reduces the risk of misreading information). Eventually, this is expected to increase the reconfigurability capability of the manufacturing system in terms of achieving faster reconfiguration and ramp-up.

The categorization of aspects led to the identification of a so-called 3-e model. The following table (Table 1) gathers literature-based observations justifying the identification of the three aspects. 
Table 1. A classification of aspects of shop floor digitalisation supporting operators in enhancing the diagnosability

\begin{tabular}{|c|c|c|c|}
\hline Reference & Error reduction & Ergonomics of the solution & $\begin{array}{l}\text { Easiness of } \\
\text { consultation/declarations }\end{array}$ \\
\hline $\begin{array}{l}\text { Belli et al. } \\
2019 \text { [22] }\end{array}$ & $\begin{array}{l}\text { - Compared to imputing } \\
\text { virtual data, data hand- } \\
\text { writing is easily prone to } \\
\text { errors and alterations; indeed, } \\
\text { shop floor interfaces can be } \\
\text { designed in order to highlight } \\
\text { problems to operators and to } \\
\text { reduce their errors (e.g. non- } \\
\text { compliant data may be } \\
\text { automatically highlighted). }\end{array}$ & $\begin{array}{l}\text { - The use of mobile devices - } \\
\text { in particular, tablets - } \\
\text { represents a viable and } \\
\text { efficient solution where the } \\
\text { use of PCs is not possible } \\
\text { (e.g. next to factory lines). }\end{array}$ & $\begin{array}{l}\text { - The log-in process, required } \\
\text { to operators to access and } \\
\text { provide shop floor, should be } \\
\text { adequately easy. } \\
\text { - Home pages should be } \\
\text { appropriately designed and } \\
\text { customized according to } \\
\text { operators' profiles and roles. } \\
\text { Indeed, an essential feature } \\
\text { required in the digitalisation } \\
\text { process started by companies, } \\
\text { is the possibility to find data } \\
\text { of interest in a simple way. }\end{array}$ \\
\hline
\end{tabular}

Bortolini

et al. 2018

[27]

\begin{abstract}
- A digital solution should accurately record and capitalize the activities of the human body, proposing a virtual representation of the skeleton and its movements during the execution of tasks. Thus, it should propose a set of quantitative indicators to monitor the operator's health while he/she is working.
\end{abstract}

\begin{tabular}{ll}
\hline Galaske et & - Instead of making decisions \\
al. 2018 & based on individual \\
{$[25]$} & knowledge, solutions should \\
& tend to be made by intelligent \\
& systems where humans only \\
& intervene in the case of \\
& emergency.
\end{tabular}

- Instead of static paper-based work instruction, solutions should tend to be interactive and adaptive assistance systems, which provide information for the worker based on his/her qualification and the current situation.

- Operators who have been working with traditional techniques have often valuable experience in their job. For this reason, a digital system should not require them to have technological skills, for instance the use of screens and buttons can be substituted by gesture-based interfaces, which are much more intuitive. 


\begin{tabular}{|c|c|c|c|}
\hline Reference & Error reduction & Ergonomics of the solution & $\begin{array}{l}\text { Easiness of } \\
\text { consultation/declarations }\end{array}$ \\
\hline $\begin{array}{l}\text { Masood } \\
\text { and Egger } \\
2019 \text { [23] }\end{array}$ & $\begin{array}{l}\text { - AR can be used to support } \\
\text { assembly operations, either in } \\
\text { training or as an online } \\
\text { guidance system for } \\
\text { operators. For example, in } \\
\text { logistic, 'pick-by-vision' is a } \\
\text { prominent concept utilising } \\
\text { AR to indicate picking } \\
\text { locations and quantities. }\end{array}$ & & \\
\hline
\end{tabular}

\begin{tabular}{ll}
\hline Murauer & - Using AR-systems, workers \\
& can be supported in their \\
& work. Especially, head- \\
& mounted displays (HMD) or \\
& smart glasses offer the \\
& advantage of working hands- \\
& free. In addition, the \\
& visualization of work task \\
& instructions can help the \\
& worker in avoiding \\
unnecessary head or body & movements.
\end{tabular}

Pfeffer et - Virtual Reality (VR) - The size of interactive - Compared to mouse and al. 2015 provides the ability to quickly surfaces ranges from keyboard, touch, multi-touch

[29] represent a product close to reality and true to scale. VR supports tasks based on information derived from many sources. For instance, hazardous situations, operation, maintenance, and training scenarios can be examined with the help of virtual product models. surfaces ranges from
smartphones or tablets over laptops to even large, wallsized displays. They can complement each other for solving particular tasks, for example large displays can be used for tasks like information visualisation, allowing users to see both overview and detail at the same time. and digital pens as input devices offer the advantage of enabling direct manipulation of data by merging input and output to a more natural form of interaction.

- To ensure a satisfying user experience, user interfaces on all devices should be designed so to make switches between them as seamless as possible.

\begin{tabular}{|c|c|c|c|}
\hline $\begin{array}{l}\text { Richter et } \\
\text { al. } 2017 \\
{[21]}\end{array}$ & $\begin{array}{l}\text { Operators should have a } \\
\text { "personal" information feed } \\
\text { that could support their } \\
\text { activities and empower them. }\end{array}$ & $\begin{array}{l}\text { - Due to the numerous and } \\
\text { varied challenges which } \\
\text { maintenance personnel face } \\
\text { (such as the need to move a } \\
\text { lot), it is important that } \\
\text { workers are provided with the } \\
\text { necessary information in a } \\
\text { bundled, contextual and } \\
\text { mobile way. This can be done } \\
\text { through the implementation } \\
\text { of a mobile employee- } \\
\text { centred knowledge } \\
\text { management system. }\end{array}$ & $\begin{array}{l}\text { - Better access to digitalised } \\
\text { information and analytics } \\
\text { would allow for cutting } \\
\text { production times while } \\
\text { increasing product quality } \\
\text { and reducing waste due to } \\
\text { making better-informed } \\
\text { decisions and detecting } \\
\text { patterns and trends in product } \\
\text { deviations. }\end{array}$ \\
\hline
\end{tabular}




\begin{tabular}{|c|c|c|c|}
\hline Reference & Error reduction & Ergonomics of the solution & $\begin{array}{l}\text { Easiness of } \\
\text { consultation/declarations }\end{array}$ \\
\hline $\begin{array}{l}\text { Romero et } \\
\text { al. } 2017 \\
{[13]}\end{array}$ & $\begin{array}{l}\text { - Approaches like "digital } \\
\text { poka-yokes" in order to avoid } \\
\text { human error (i.e. perception, } \\
\text { judgment, action errors) and } \\
\text { provide a virtual safety net } \\
\text { will support the Operator } 4.0 \text {. }\end{array}$ & & $\begin{array}{l}\text { - "(Active) interface agents" } \\
\text { represent a set of interaction } \\
\text { rules and conditions for } \\
\text { supporting humans and } \\
\text { machines interfacing with the } \\
\text { rest of a system; their 'active' } \\
\text { feature allows the interface } \\
\text { agent to constantly learn and } \\
\text { evolve its rules in order to be } \\
\text { able to personalise the } \\
\text { assistance to its user (humans } \\
\text { or machines). }\end{array}$ \\
\hline
\end{tabular}

\begin{tabular}{ll}
\hline Sun et al. & - Smart wearables enable \\
& hands-free information \\
& processing for shop floor \\
& workers. Such items not only \\
& help operator finishing \\
& tasks, but also motivate them \\
& as they act as their assistants, \\
& not as their replacement. \\
& Furthermore, wearable \\
& technology allows collecting \\
& biometric data, which is \\
& useful for monitoring \\
& employee's health status.
\end{tabular}

Umer et al. - The information exchange

2018 [12] at shop floor level allows quick decisions based on data related to equipment, such a result is hardly achieved using traditional hierarchical MES systems.
- The visualization of useful information in the shop floor makes the problem-solving process immediate and simpler, thus improving the quality of the product.

- Analysed data can be provided in a customized way, according to the needs of the different users which may be tightening experts, maintenance engineers and process engineers.

\begin{tabular}{|c|c|c|}
\hline $\begin{array}{l}\text { Wurhofer } \\
\text { et al. } 2018 \\
\text { [26] }\end{array}$ & $\begin{array}{l}\text { - Providing technological } \\
\text { support in form of assistive } \\
\text { systems can help reducing } \\
\text { cognitive load of human } \\
\text { workers. For example, } \\
\text { assistive systems can offer } \\
\text { step-by-step instructions for } \\
\text { specific tasks, support } \\
\text { humans in trouble shooting, } \\
\text { or store information which } \\
\text { can be dynamically } \\
\text { requested. }\end{array}$ & $\begin{array}{l}\text { The use of mobile } \\
\text { - like } \\
\text { technologies access to information, } \\
\text { smartphones, laptops, or however, operators need } \\
\text { tablets allows workers having } \\
\text { necessary imple procedures to consult } \\
\text { everywhere. For example, the } \\
\text { deployment of tablets for } \\
\text { maintenance makes } \\
\text { maintenance engineers' work } \\
\text { much more comfortable, } \\
\text { respectively, as they have to } \\
\text { walk much less than before. }\end{array}$ \\
\hline
\end{tabular}


Summarising the results of the literature review, the three classes of aspects of shop floor digitalisation supporting operators in enhancing the diagnosability can be described as follows:

- $\quad$ error reduction through either error-proof mechanism or the enhancement of operators knowledge. It refers to the exploitation of digital technologies such as AR or assistive mechanisms to allow operators to either learn in virtual environments intuitively and extensively or to reduce their cognitive load. In addition, operators are empowered by personalised information, customised for their needs and skills;

- ergonomics of the solution. Many aspects contribute to the ergonomics of a solution: sizes and functionalities of interactive surfaces, mobility, weight and wear-ability of interactive surfaces. The more a digital solution simplifies/ supports the proper and safe execution of their tasks, the greater it is ergonomic for operators;

- easiness of consultation/ declarations. Interactions with digital solutions should possibly be easily made, operators shouldn't waste time to access solutions or to search for needed information. In other words, solutions should preferably have user-friendly interfaces, thus reducing the load of IT skills needed by operators to do their job.

\section{Insights from the case study}

A large international company, which further details are not provided for confidentiality reasons, is currently implementing an experimental project aimed at the digitalisation of the entire factory. In the company, operators are involved in the digitalisation process and are asked to provide digital feedback on manufacturing processes in order to achieve increased and improved control and reaction to factory events. This solution is expected to enhance shop floor diagnosability. Moreover, the company faces rapidly changing production requirements, which means that reconfigurability capability is an important parameter to the company. Indeed, the digitalisation project is expected to support such parameter.

As the case company has both high expertise on manufacturing processes and a long history of tradition within their field and industry, company know-how is largely passed down through coaching and mentoring activities (i.e. being tacit knowledge) and most of the information exchanges are not tracked or documented. For this reason, the company is experiencing a huge effort in implementing the digitalisation project and is thus highly interested in identifying directions to gradually improve the adopted digital solutions. Therefore, the case is appropriate for applying the 3-e model as a tool for analysis and identification of further directions to enhance digitalisation as a means for operator support. The 3-e model (see Table 2) was applied to analyse the case and provide directions to the management of the company. Thus, the results in Table 2 not only frame the current situation of the company according to the three aspects enhancing diagnosability, but also indicate future solution improvements driven by these three aspects. 
The company has just started the experimental project of shop floor digitalisation. As summarised in Table 2, incremental improvements to the solution, in terms of error reduction, ergonomics and easiness of consultation/declaration, will enhance shop floor diagnosability. Specifically: (i) poka yoka mechanisms and alerts will prevent operators from making mistakes; (ii) the introduction of wider screens and/or mobile devices will simplify the execution of tasks and allow operators to save time (thus improving their productivity); (iii) an easier access to software interfaces will also speed up operators in doing their job and in eventually notifying any reliability/quality problem to the maintenance department. In turn, increased diagnosability will enhance the reconfigurability capability of the company in facing rapidly changing production requirements.

Table 2. Analysis of the case according to the 3-e model and directions for improvements

\begin{tabular}{l} 
Error reduction \\
\hline - Operators have to declare \\
materials consumptions to the \\
shop floor (IT) system. \\
Currently, a list of materials \\
automatically appears on activity \\
screens after such materials have \\
been supplied to the production \\
line. Operators should make sure \\
that the materials they are \\
physically using are really those \\
they read on the list. After their \\
check, they just click the \\
"consumption" button on system \\
interface. Thus, there is no \\
mechanism to track the materials \\
really used by operators (no \\
correction in case of mistakes). In \\
the near future, some of the \\
critical materials will be labelled \\
with barcodes and operators will \\
be provided with barcode readers \\
directly communicating with the \\
software solution so they will \\
have to really input used \\
materials (and the software will \\
be able to compare used material \\
to the one supplied by the \\
logistics department). \\
Furthermore, comparing used \\
materials to those indicated in \\
technical prescriptions, the \\
system will be able to alert \\
operators in case of usage of \\
wrong materials.
\end{tabular}
Ergonomics of the solution Easiness of consultation/ declarations

- At many departments, operators are instructed about assigned tasks and access documents and drawings by consulting very small and fixed screens (totems). This not only does not allow them to easily read documentation, but also forces them to constantly move around the shop-floor. In the near future, mobile solutions such as carts provided with wide industrial laptops will be introduced.

- At some machining departments, panel pc's are placed nearby machines, however, operators supervising such machines have also the responsibility to measure the dimensions of the produced pieces and report them to the software. Currently, some of the desks for the measures are far from the panel pc. Thus, they are temporarily forced to annotate taken measures on paper and then report them on the pc. The introduction of tablets could solve this issue.
- Currently, to start working, operators have to wait for supervisors' verbal directions and, after the log-in, they need to input the order identificator and search their assigned tasks. Indeed, assigned tasks are not already available on operators' home pages as the scheduler software does not yet communicate with the shop floor software (thus also prints of scheduled activities are required). In the next year, system architecture will be adequately modified: after the log-in, operators will automatically be redirect on their personal list of tasks.

- The $\log$ in process requires operators to insert their individual credentials; this is time consuming and annoying for operators. In future, predisposing some badge readers associated to the hardware exploited to access the software will solve this problem. 


\begin{tabular}{|c|c|c|}
\hline Error reduction & Ergonomics of the solution & $\begin{array}{l}\text { Easiness of consultation/ } \\
\text { declarations }\end{array}$ \\
\hline $\begin{array}{l}\text { - Operators have to type on a } \\
\text { keyboard the serial number of } \\
\text { used equipment to let the system } \\
\text { know about their usage (this } \\
\text { input is needed for the activity of } \\
\text { equipment lifecycle } \\
\text { management). Each equipment is } \\
\text { accurately designed for specific } \\
\text { products. At the moment, there is } \\
\text { no poka yoka mechanism to } \\
\text { alert/stop him/her in case of }\end{array}$ & & $\begin{array}{l}\text { - Operators have to type on a } \\
\text { keyboard the serial number of } \\
\text { used equipment to let the system } \\
\text { know about their usage. In the } \\
\text { near future equipment will be } \\
\text { labelled with barcodes and } \\
\text { operators will be provided with } \\
\text { barcode readers directly } \\
\text { communicating with the software } \\
\text { solution (thus operators will save } \\
\text { time). }\end{array}$ \\
\hline $\begin{array}{l}\text { wrong equipment as the shop } \\
\text { floor system is not yet provided } \\
\text { with this information. In the } \\
\text { future, the PLM software will } \\
\text { communicate this kind of } \\
\text { information to the shop floor } \\
\text { system, thus alerting the operator } \\
\text { in case of use of wrong } \\
\text { equipment. }\end{array}$ & & $\begin{array}{l}\text { At this first stage, supervisors are } \\
\text { required to access and know how } \\
\text { to use multiple software, as the } \\
\text { solution is not integrated yet with } \\
\text { other software used in the } \\
\text { company. For example, when } \\
\text { checking operators work, } \\
\text { supervisors can not see on their } \\
\text { dashboard their workers until } \\
\text { they start some activities on the } \\
\text { shop floor software, this is due to } \\
\text { the fact that the software used in } \\
\text { the shop floor does not yet } \\
\text { exchange information with the } \\
\text { software recording the badging } \\
\text { activity of operators. As a result, } \\
\text { idle operators may not be quickly } \\
\text { identified. Software integration } \\
\text { would make easier any } \\
\text { supervision task. }\end{array}$ \\
\hline
\end{tabular}

\section{Conclusions and directions for future research}

This paper provides a literature-based model that summarises the aspects of shop floor digitalisation supporting operators in enhancing the diagnosability and thus the reconfigurability of manufacturing systems. Insights from a case study are interpreted through the model to both consolidate the theoretical results and show the implications of this study for practitioners. Indeed, the findings of this paper indicate that the model can support practitioners in taking specific actions related to digitalisation to improve operator-dependent diagnosability. Thus, in future research the model may further evolve to become an assessment tool for companies involved in a process of shop floor digitalisation and aiming at enhancing diagnosability (i.e. quality and reliability of production processes). Such a tool is particularly relevant when companies strive to achieve a higher level of reconfigurability in manufacturing, as the advantage of reconfigurability is lost without corresponding high levels of diagnosability.

This research provides various insights for future research. First of all, six characteristics of reconfigurability exist and research activity on how such characteristics can be strengthened by factory digitalisation is still missing even if interesting insights have been provided by some authors, see for example Rösiö et al. [10]. In the authors opinion, not only diagnosability, but also customization can be positively affected by digitalisation. Seeing system lifecycle as the succession of two different periods - system 
configurations and system reconfigurations -, customization is the ability to eventually reconfigure the system according to changed market requirements. Thus customization is highly relevant, as it is the trigger of reconfigurability [31]. In a fully digitalised factory, when product engineering departments design new products and corresponding processing cycles according to changed market requirements, they can make new instruction at shop floor level available just relying on system integration (i.e. integration between a PLM and a MES). Moreover, skills and competences could be property shaped by relying on augmented reality.

As final remark, shop-floor digitalisation also involves an increase of operators' skills and responsibilities (such as IT skills, the use of new devices and the need to either support or make decisions to solve specific issues); such aspect, together with the need for a proper change management, has not been addressed in this research but certainly deserves further investigation.

\section{References}

[1] Y. Koren and M. Shpitalni, "Design of reconfigurable manufacturing systems," Journal of Manufacturing Systems, vol. 29, no. 4, pp. 130-141, 2010.

[2] M. G. Mehrabi, A. G. Ulsoy, and Y. Koren, "Reconfigurable manufacturing systems and their enabling technologies," International Journal of Manufacturing Technology and Management, vol. 1, no. 1, pp. 1-21, 2000.

[3] A.-L. Andersen, T. D. Brunoe, B. Christensen, and M. Bejlegaard, "Tailored Reconfigurability: A Comparative Study of Eight Industrial Cases with Reconfigurability as a Key to Manufacturing Competitiveness," in Reconfigurable Manufacturing Systems: From Design to Implementation, 2019, pp. 209-245.

[4] Y. Koren, "General RMS Characteristics. Comparison with Dedicated and Flexible Systems," in Chapter 3 in Reconfigurable Manufacturing Systems and Transformable Factories, no. 1, 2006, pp. 27-45.

[5] M. R. Abdi, "Fuzzy multi-criteria decision model for evaluating reconfigurable machines," International Journal of Production Economics, vol. 117, no. 1, pp. 1-15, 2009.

[6] C. Rösiö, Supporting the design of reconfigurable production systems, no. 130. 2012.

[7] D. R. Sjödin et al., "Smart Factory Implementation and Process Innovation Smart Factory Implementation and Process Innovation A Preliminary Maturity Model for Leveraging Digitalization in Manufacturing," Research-Technology Management, vol. 61, no. 5, pp. 22-31, 2018.

[8] A. Reitze, J. Nikolas, S. Lier, M. Kohnke, J. Riese, and M. Gr, "Roadmap for a Smart Factory : A Modular, Intelligent Concept for the Production of Specialty Chemicals Minireviews," pp. 42424247, 2018.

[9] G. P. Monizza, R. A. Rojas, and E. Rauch, "A Case Study in Learning Factories for Real- Time Recon fi guration of Assembly Systems Through Computational Design and Cyber- Physical Systems," in Chiabert P., Bouras A., Noël F., Ríos J. (eds) Product Lifecycle Management to Support Industry 4.0. PLM 2018. IFIP Advances in Information and Communication Technology, vol. 2, Springer International Publishing, 2018, pp. 227-237.

[10] C. Rösiö, T. Aslam, K. Banavara, and S. Shetty, "Towards an assessment criterion of reconfigurable manufacturing systems within the automotive industry," in Procedia Manufacturing, 2019, vol. 28, pp. $76-82$.

[11] A. Calà et al., "Migration towards Digital Manufacturing Automation - an Assessment Approach," in IEEE Industrial Cyber-Physical Systems (ICPS), 2018, pp. 714-719.

[12] M. Umer, B. Mahesh, L. Hanson, M. R. Khabbazi, and M. Onori, "Smart Power Tools: An Industrial Event-Driven Architecture Implementation," in ScienceDirect 51st CIRP Conference on Manufacturing Systems, 2018, pp. 1357-1361.

[13] D. Romero, T. Wuest, J. Stahre, and D. Gorecky, "Social Factory Architecture: Social Networking Services and Production Scenarios Through the Social Internet of Things, Services and People for the Social Operator 4.0," in APMS 2017: Advances in Production Management Systems. The Path to Intelligent, Collaborative and Sustainable Manufacturing, 2017, pp. 265-273. 
[14] A. Beauville, N. Klement, O. Gibaru, L. Roucoules, and L. Durville, "Identification of reconfigurability enablers and weighting of reconfigurability characteristics based on a case study," in Procedia Manufacturing, 2019, vol. 28, pp. 96-101.

[15] H. Elmaraghy, "Smart changeable manufacturing systems," in Procedia Manufacturing, 2018 , vol. 28, pp. 3-9.

[16] H. P. Wiendahl et al., "Changeable Manufacturing - Classification, Design and Operation," CIRP Annals - Manufacturing Technology, vol. 56, no. 2, pp. 783-809, 2007.

[17] C. F. Durach, J. Kembro, and A. Wieland, "A New Paradigm for Systematic Literature Reviews in Supply Chain Management,” Journal of Supply Chain Management, vol. 53, no. 4, pp. 67-85, 2017.

[18] R. K. Yin, Case Study Research, 2nd editio. SAGE, 1994.

[19] M. Ketokivi and T. Choi, "Renaissance of case research as a scientific method," Journal of Operations Management, vol. 32, no. 5, pp. 232-240, 2014.

[20] C. Voss, N. Tsikriktsis, and M. Frohlich, "Case research in operations management," International Journal of Operations \& Production Management, vol. 22, no. 2, pp. 195-219, 2002.

[21] A. Richter, S. Vodanovich, M. Steinhuser, and L. Hannola, "IT on the Shop Floor - Challenges of the Digitalization of Manufacturing Companies," in 30th Bled eConference: Digital Transformation - From connecting things to transforming our lives, 2017.

[22] L. Belli, L. Davoli, A. Medioli, P. L. Marchini, and G. Ferrari, "Toward Industry 4 . 0 With IoT: Optimizing Business Processes in an Evolving Manufacturing Factory," Frontiers in ICT, vol. 6, no. 17, pp. 1-14, 2019.

[23] T. Masood and J. Egger, "Augmented reality in support of Industry 4.0 - Implementation challenges and success factors," Robotics and Computer-Integrated Manufacturing, vol. 58, pp. 181-195, 2019.

[24] N. Murauer, "Design Thinking: Using Photo Prototyping for a user-centered Interface Design for Pick-by-Vision Systems," in PETRA '18 Proceedings of the 11th PErvasive Technologies Related to Assistive Environments Conference, 2018, pp. 126-132.

[25] N. Galaske, A. Arndt, H. Friedrich, K. D. Bettenhausen, and R. Anderl, "Workforce Management 4.0 - Assessment of Human Factors Readiness Towards Digital Manufacturing," in Advances in Ergonomics of Manufacturing: Managing the Enterprise of the Future, Advances in Intelligent Systems and Computing 606, 2018, vol. 1, pp. 106-115.

[26] D. Wurhofer, T. Meneweger, V. Fuchsberger, and M. Tscheligi, "Reflections on Operators' and Maintenance Engineers ' Experiences of Smart Factories," in GROUP '18 Proceedings of the 2018 ACM Conference on Supporting Groupwork, 2018, pp. 284-296.

[27] M. Bortolini, M. Faccio, M. Gamberi, and F. Pilati, "Motion Analysis System ( MAS ) for production and ergonomics assessment in the manufacturing processes," Computers \& Industrial Engineering, pp. 1-13, 2018.

[28] C. Garrido-Hidalgo, D. Hortelano, L. Roda-sanchez, T. Olivares, M. C. Ruiz, and V. Lopez, "IoT Heterogeneous Mesh Network Deployment for Human-in-the-Loop Challenges Towards a Social and Sustainable Industry 4 . 0," IEEE Access, vol. 6, pp. 28417-28437, 2018.

[29] J. Pfeffer, M. Graube, P. Reipschlaeger, and S. Arndt, "Towards Collaborative Plant Control using a Distributed Information and Interaction Space," in 2015 IEEE 20th Conference on Emerging Technologies \& Factory Automation (ETFA), 2015, pp. 1-4.

[30] J. Sun, M. Gao, Q. Wang, M. Jiang, X. Zhang, and R. Schmitt, "Smart Services for Enhancing Personal Competence in Industrie 4.0 Dgital Factory," LogForum Scientific Journal of Logistics, vol. 14, no. 1, pp. 51-57, 2018.

[31] A. Napoleone, A. Pozzetti, and M. Macchi, "A framework to manage reconfigurability in manufacturing," International Journal of Production Research, vol. 56, no. 11, pp. 3815-3837, 2018. 